\title{
Influence of wound closure on the volume stability of particulate and non-particulate GBR materials: an in vitro cone-beam computed tomographic examination. Part II
}

Mir-Mari, Javier ; Benic, Goran I ; Valmaseda-Castellón, Eduard ; Hämmerle, Christoph H F ; Jung, Ronald E

\begin{abstract}
OBJECTIVES To test whether GBR with an L-shaped soft-block bone substitute and particulate bone substitute differs from GBR with particulate bone substitute as regards the volume stability of the augmented region during flap closure. MATERIALS AND METHODS Twenty peri-implant box-shaped bone defects were created in 10 pig mandibles. Every bone defect was augmented with each of the following two GBR procedures in turn: control group - particulate xenograft applied buccally + collagen membrane + pins; test group - particulate xenograft applied buccally + L-shaped soft-block xenograft applied buccally and occlusally + collagen membrane + pins. Cone-beam computed tomography scans were obtained before and after wound closure. The horizontal thickness (HT) of the augmented region (bone substitute + membrane) was assessed at the implant shoulder (HT0 $\mathrm{mm}$ ) and at $1 \mathrm{~mm}$ to $5 \mathrm{~mm}$ apical to the implant shoulder (HT1 mm -HT5 mm ). In the test group, the vertical thickness (VT) and $45^{\circ}$ thickness (45-T) of the augmented region were measured from the implant shoulder. The changes in HT during flap suturing were calculated as absolute $(\mathrm{mm})$ and relative values (\%). Repeated-measures ANOVAs were used for statistical analysis. RESULTS The reduction in HT0 mm was $20.5 \pm 23.3 \%$ (SD) in the control group and $2.4 \pm 9.2 \%(\mathrm{SD})$ in the test group $(\mathrm{P}=0.014)$. There were no statistically significant differences in changes in HT1-5 mm between the groups $(\mathrm{P}>0.05)$. In the test group, the reduction in VT amounted to 28.0 $\pm 11.9 \%$ (SD) and the reduction in 45-T amounted to $24.8 \pm 10.2 \%$ (SD) $(\mathrm{P}<0.001)$. CONCLUSION The addition of an L-shaped soft-block bone substitute to a particulate xenograft, covered by a collagen membrane and fixed with pins, significantly improved the horizontal volume stability of the augmented region during wound closure.
\end{abstract}

DOI: https://doi.org/10.1111/clr.12845

Posted at the Zurich Open Repository and Archive, University of Zurich ZORA URL: https://doi.org/10.5167/uzh-127135

Journal Article

Originally published at:

Mir-Mari, Javier; Benic, Goran I; Valmaseda-Castellón, Eduard; Hämmerle, Christoph H F; Jung, Ronald E (2017). Influence of wound closure on the volume stability of particulate and non-particulate GBR materials: an in vitro cone-beam computed tomographic examination. Part II. Clinical Oral Implants Research, 28(6):631-639.

DOI: https://doi.org/10.1111/clr.12845 
Influence of wound closure on the volume stability of particulate and nonparticulate GBR materials: an in vitro cone beam computed tomographic examination. Part II.

\section{Authors:}

Mir-Mari, Javier ${ }^{1}$; Benic, Goran I. ${ }^{2}$; Valmaseda-Castellón, Eduard ${ }^{1}$; Hämmerle, Christoph H.F.' ${ }^{2}$ Jung, Ronald E. ${ }^{2}$

\section{Authors' affiliations:}

${ }^{1}$ Oral Surgery and Implantology Department, Dental School, University of Barcelona, Barcelona, Spain

${ }^{2}$ Clinic of Fixed and Removable Prosthodontics and Dental Material Science, Center of Dental Medicine, University of Zurich, Zurich, Switzerland

\section{Key words:}

bone, regeneration, alveolar ridge augmentation, guided bone regeneration, guided tissue regeneration, membrane, collagen, bone substitutes, soft-block, granulate, graft, pin, tack, dental implants, cone-beam computed tomography, in vitro

\section{Running title:}

Volume stability management during GBR procedures

\section{Corresponding author:}

Dr. Javier Mir-Mari

Facultat d'Odontologia - Universitat de Barcelona

Campus de Bellvitge Pavelló de Govern 2a planta, Despatx 2.9

08907 L'Hospitalet de Llobregat, Spain

E-mail: jmirmari@gmail.com 


\section{ABSTRACT}

Objective: To test whether GBR with an L-shaped soft-block bone substitute and particulate bone substitute differs from GBR with particulate bone substitute as regards the volume stability of the augmented region during flap closure.

Material and methods: Twenty peri-implant box-shaped bone defects were created in 10 pig mandibles. Every bone defect was augmented with each of the following two GBR procedures in turn: control group - particulate xenograft applied buccally + collagen membrane + pins; test group - particulate xenograft applied buccally + Lshaped soft-block xenograft applied buccally and occlusally + collagen membrane + pins. Cone beam computed tomography scans were obtained before and after wound closure. The horizontal thickness (HT) of the augmented region (bone substitute + membrane) was assessed at the implant shoulder $\left(\mathrm{HT}_{0 \mathrm{~mm}}\right)$ and at $1 \mathrm{~mm}$ to $5 \mathrm{~mm}$ apical to the implant shoulder $\left(\mathrm{HT}_{1 \mathrm{~mm}}-\mathrm{HT}_{5 \mathrm{~mm}}\right)$. In the test group, the vertical thickness (VT) and $45^{\circ}$ thickness (45-T) of the augmented region were measured from the implant shoulder. The changes in HT during flap suturing were calculated as absolute (mm) and relative values (\%). Repeated-measures ANOVAs were used for statistical analysis.

Results: The reduction in $\mathrm{HT}_{0 \mathrm{~mm}}$ was $20.5 \pm 23.3 \%$ (SD) in the control group and 2.4 $\pm 9.2 \%(S D)$ in the test group $(p=0.014)$. There were no statistically significant differences in changes in $\mathrm{HT}_{1-5 \mathrm{~mm}}$ between the groups $(\mathrm{p}>0.05)$. In the test group, the reduction in VT amounted to $28.0 \pm 11.9 \%$ (SD) and the reduction in $45-\mathrm{T}$ to 24.8 $\pm 10.2 \%(S D)(p<0.001)$.

Conclusion: The addition of an L-shaped soft-block bone substitute to a particulate xenograft, covered by a collagen membrane and fixed with pins, significantly improved the horizontal volume stability of the augmented region during wound closure. 


\section{INTRODUCTION}

Guided Bone Regeneration (GBR) in combination with simultaneous implant placement has become a routine treatment approach in implantology. This procedure allows recovery of an adequate bone anatomy and prosthetically-driven dental implant positioning (Benic \& Hämmerle 2014). Consistent, reliable bone regeneration using a granular demineralized bovine bone mineral (DBBM) in combination with a resorbable collagen membrane has been reported (Benic et al. 2009; Zumstein et al. 2012; Jung et al. 2013). Despite these good GBR results, the mechanical properties and clinical behaviour of the augmented region during wound closure and healing are still not well known.

Primary stability of the bone graft is a prerequisite for the success of GBR. Defect anatomy, mechanical characteristics of the filling material and flap closure manoeuvres (Lorenzoni et al. 1998; Zitzmann et al. 1999; Carpio et al. 2000; Von Arx et al. 2001) are some of the features that have been related to the initial stability of the augmented region. The first part of the present research showed significant material displacement due to compression during wound closure (Mir-Mari et al 2015) and compared different GBR approaches, revealing that applying fixation pins and using block bone substitute instead of a particulate grafting material significantly enhanced the volume stability of the augmented region.

A variety of strategies have been proposed to avoid material displacement. The primary stability of the GBR materials can be increased either by improving the mechanical properties of the membrane or by enhancing the dimensional stability of the bone graft. The use of non-resorbable titanium-reinforced membranes is one of the most-documented options for this purpose (Dahlin et al. 1995; Fugazzotto 1997; Zitzmann et al. 1997). However, the main clinical drawback associated with nonresorbable membranes is the high risk of mucosal dehiscences and infectious complications (Chiapasco \& Zaniboni 2009). The use of one-piece bone blocks instead of granular bone substitutes has been proved to reduce material displacement and compensate for compression during suture (Mir-Mari et al. 2015).

Despite the excellent mechanical properties of block grafts, clinical handling and precise adaptation to the peri-implant defect can be challenging (Zecha et al 2011; Mir-Mari et al 2015, Benic et al. 2015). A decade ago, in the context of alveolar ridge preservation, a soft-type block in which DBBM particles are incorporated into a 
collagen matrix was developed (Nevins et al. 2003; Jung et al. 2004; Sculean et al. 2005). This combination provides the material with enough flexibility and compression capability to improve both the clinical handling and the adaptation to the bone defect (Jung et al 2013).

The present study was designed as the second part of a research project that aimed to assess the volume stability of different regeneration materials during wound closure. In the first part, even though the use of pins or of block bone substitutes proved to enhance graft stability, a $20 \%$ reduction in horizontal thickness was still detected at implant collar level (Mir-Mari et al. 2015). In order to overcome the horizontal loss and increase GBR stability at implant collar level, a new regeneration technique using an Lshaped soft-block bone substitute was proposed. This technique was investigated in the present in vitro study.

The aim of the present study was to test whether or not the addition of an L-shaped soft-block bone substitute to the particulate bone substitutes enhances volume stability during flap closure compared to particulate bone substitutes alone.

\section{MATERIAL AND METHODS}

The present in vitro study was designed as part II of a previous publication (Mir-Mari et al 2015). It also serves to validate that same study. Hence, the model has already been described in detail (Mir-Mari et al 2015).

\section{In vitro model}

Twenty box-shaped bone defects were created in 10 five-month-old pig mandibles. Two defects per mandible were created symmetrically and bilaterally. The bone defects measured $8 \mathrm{~mm}$ mesio-distally, $3 \mathrm{~mm}$ bucco-orally and $6 \mathrm{~mm}$ apico-coronally (Fig. 1). One titanium implant (OsseoSpeed ${ }^{\mathrm{TM}} \mathrm{S}$, ASTRA TECH Implant System, DENTSPLY Implants, Mannheim, Germany), $8 \mathrm{~mm}$ long and $4 \mathrm{~mm}$ in diameter, was inserted into each bone defect (Fig. 1.). A more detailed description of the in vitro model can be consulted in part I of this research project (Mir-Mari et al. 2015). 


\section{GBR and wound closure}

A new regeneration technique was proposed to increase GBR stability at implant collar level. In order to assess the improvement, the new technique was compared with a particulate xenograft alone, covered by a collagen membrane and fixed with titanium pins. Hence, the following two GBR procedures were randomly assigned by casting a die (Fig. 2):

- Particulate bone substitute alone (control): particulate DBBM (Bio-Oss ${ }^{\circledR}$ granules 0.25-1 mm, Geistlich Pharma AG, Wolhusen, Switzerland) + collagen membrane (Bio-Gide ${ }^{\circledR}$, Geistlich Pharma AG, Wolhusen, Switzerland) + two titanium pins (Frios $^{\circledR}$ membrane tacks, DENTSPLY Implants, Mannheim, Germany) $(n=20)$.

- L-shaped soft-block bone substitute (test): particulate DBBM (Bio-Oss ${ }^{\circledR}$ granules 0.25-1 mm, Geistlich Pharma AG, Wolhusen, Switzerland) + SoftBlock ( $90 \%$ DBBM granules stabilized with $10 \%$ porcine collagen) formed into an L shape (Bio-Oss ${ }^{\circledR}$ collagen, 250 mg, 0.4-0.5 cc, Geistlich Pharma AG, Wolhusen, Switzerland) + collagen membrane (Bio-Gide ${ }^{\circledR}$, Geistlich Pharma AG, Wolhusen, Switzerland) + two titanium pins (Frios ${ }^{\circledR}$ membrane tacks, DENTSPLY Implants, Mannheim, Germany) $(n=20)$.

Each bone defect $(n=20)$ was augmented once with each of the two GBR procedures under study. The order of application was randomly assigned by casting a die. Eleven defects received the test group procedure as the first treatment. Accordingly, nine defects received the control group procedure first. Prior to the GBR procedures, the different bone substitute materials were soaked in a $50 \%$ aqueous solution of a radioopaque contrast medium (Gastrografin ${ }^{\circledR}$, Bayer, Zurich, Switzerland).

In the control group (particulate bone substitutes alone), the procedure was applied following the same protocol as described previously (Mir-Mari et al 2015). The particulate bone substitute was applied to the buccal surface of the implant and alveolar ridge, aiming to achieve $1 \mathrm{~mm}$ of over-contour (Fig. 2a). Standardized overaugmentation was guaranteed by using a silicone guide. A collagen membrane was then applied to cover the bone substitute and overlap the walls of the defect by at least $2 \mathrm{~mm}$. Finally, the membrane was stabilized by means of two titanium pins placed $1 \mathrm{~mm}$ apically to the apical wall of the defect. 
In the case of the Test group (L-shaped soft-block bone substitute), the particulate bone substitute was applied to the buccal surface of the implant and alveolar ridge in exactly the same way as for the control group. A rectangular soft-block of DBBM was then cut extraorally into an L-shaped block with a No15 surgical blade. A periodontal probe was used to ensure a homogeneous thickness of $3 \mathrm{~mm}$ in the occlusal portion of the $\mathrm{L}$. The thickness of the buccal portion was $2 \mathrm{~mm}$ (Fig. 2b). The L-shaped soft-block was applied on top of the particulate xenograft, aiming to achieve $3 \mathrm{~mm}$ of overcontour both vertically and horizontally (Fig. 2b, 2c and 2d). A collagen membrane was then applied to cover the bone substitute and overlap the walls of the defect by at least $2 \mathrm{~mm}$. Finally, the membrane was stabilized by means of two titanium pins placed $1 \mathrm{~mm}$ apically to the apical wall of the defect (Fig. 2e).

A periosteal releasing incision was performed in the apical portion of the buccal mucoperiosteal flap. The flaps were sutured with a polyamide monofilament suture (Dafilon ${ }^{\circledR}$ 5-0, B. Braun Medical AG, Sempach, Switzerland). One operator performed a standard suturing procedure (one interrupted horizontal mattress and four simple interrupted sutures per site) (Fig. 2f).

Prior to applying the subsequent GBR procedure on the same site, the sutures, membranes, pins and bone substitute were removed and the experimental site was rinsed with a $0.9 \%$ saline solution.

Two clinicians performed the experimental surgical interventions. In order to eliminate operator bias, the first operator created the peri-implant defects and performed the GBR procedures and the second clinician effected the wound closures.

\section{CBCT scanning}

Cone Beam Computed Tomography (CBCT) (KaVo Dental GmbH, Biberach, Germany) scans of the mandible were performed immediately before and after flap suturing at each site. For the scanning procedure, the jaws were placed on the supporting plate provided by the machine manufacturer, with the occlusal plane parallel to the horizontal plane, and positioned in the centre of field of view (FOV) using the laser orientation beams. The СВСТ scans were obtained with the following technical parameters: $120 \mathrm{kV}$ acceleration voltage, $5 \mathrm{~mA}$ beam current, FOV diameter $16 \mathrm{~cm}$, 
FOV height $6 \mathrm{~cm}, 600$ projections, $360^{\circ}$ rotation, voxel size $0.25 \mathrm{~mm}$ and scan time 14.7 seconds (Benic et al. 2013).

\section{CBCT image evaluation}

OsiriX ${ }^{\mathrm{TM}}$ imaging software (OsiriX v.4.0 32-bit, Pixmeo SARL, Bernex, Switzerland) was used to evaluate the CBCT DICOM datasets. The "full dynamic" visualization mode was used to set the window level (3084) and width (8168). Cross-sectional images perpendicular to the implant's central axis and the panoramic curve of the mandible were used for the measurements. The horizontal thickness of the augmented region (bone substitute + membrane) was assessed in a direction perpendicular to the implant surface at the implant shoulder $\left(\mathrm{HT}_{0 \mathrm{~mm}}\right)$ and at $1 \mathrm{~mm}, 2 \mathrm{~mm}, 3 \mathrm{~mm}, 4 \mathrm{~mm}$ and $5 \mathrm{~mm}$ apical to the implant shoulder $\left(\mathrm{HT}_{1 \mathrm{~mm}}-\mathrm{HT}_{5 \mathrm{~mm}}\right)$ (Fig. 3). To facilitate the reproducibility of the measurements, a transparent acetate foil with printed implant outlines and HT assessment levels was placed on the computer monitor over the CBCT images (Benic et al 2013).

In order to describe the flexibility and compression capability of the test group, two additional measurements were made: vertical thickness (VT) and $45^{\circ}$ thickness (45-T). VT was assessed from the implant shoulder to the most coronal point of the GBR material, following the long axis of the implant. In the case of 45-T, the thickness from the implant shoulder to the most buccal and coronal aspect of the GBR was measured in $a+45^{\circ}$ direction from the long axis of the implant (Fig. $3 b$ and $3 c$ ).

The presence of void spaces within the augmented area was assessed in order to describe the fit of the bone substitute to the bone defect. Void spaces were defined as radiolucent regions within the augmented area with a diameter of $\geq 0.5 \mathrm{~mm}$. One calibrated investigator performed all the CBCT measurements.

\section{Data analysis}

The change in HT during flap suturing was the primary outcome of the study. It was calculated as absolute $(\mathrm{mm})$ and relative value (\%) (SPSS version 20, IBM, Armonk, USA). The unit of study was peri-implant bone defect. Sample size calculation was performed for repeated measures ANOVA within factors effect, with a 0.5 effect size, a 
$=0.05$ and Power $=0.95$ using G*Power (Faul et al $2007 \& 2009$ ). Thus, a sample size of 16 defects was required. Finally, 20 defects were created and treated with each of the 2 different regeneration approaches.

Descriptive statistics were computed for all the parameters. For continuous parameters, the data distributions were represented by bar plots and boxplots. The data were reported using means, standard deviations (SD) and 95\% confidence intervals ( $95 \% \mathrm{CI}$ ). The assumption of normality was checked and confirmed by the Kolmogorov-Smirnov with the Lilliefors correction and Shapiro-Wilk tests. All the results, with exception of $45-\mathrm{T}$ in the test group, presented a normal distribution. For discrete variables, the absolute and relative frequencies were calculated.

In order to evaluate the reliability of the in vitro investigation model, the beforesuture, after-suture and change in horizontal thickness (HT) values of the "granulate + pins" group in the part I paper (Mir-Mari et al 2015) were extracted and compared with the current control group, which received the same treatment.

Repeated-measures ANOVAs were applied to detect differences in HT before suturing and differences in HT changes between the treatment procedures. The GreenhouseGeisser correction was performed when Mauchly's test ruled out sphericity. The results of tests with $p$-values of $\leq 0.05$ were considered statistically significant. For post-hoc contrasts in two- and three-factor ANOVA the Bonferroni correction was used. In case of non-normal data distribution, non-parametric paired Wilcoxon test with Bonferroni correction of the significance level was applied to test differences between the treatment procedures. Results of tests with $\mathrm{p}$-values $\leq 0.05 / 3=0.016$ were considered statistically significant.

Two weeks after the CBCT image analysis, 10 randomly selected CBCT images were re-assessed to test the intra-observer reliability of СВCT measurements. The intraclass correlation coefficient (ICC) for $\mathrm{HT}_{0 \mathrm{~mm}}-\mathrm{HT}_{5 \mathrm{~mm}}$ ranged from 0.973 to 0.989 (95\% CI: $0.932-0.996)$, indicating excellent intra-examiner agreement.

\section{RESULTS}

\section{Stability analysis}


The results of two- and three-factor ANOVA for repeated measures are presented in Tables $1 \mathrm{a}$ and $1 \mathrm{~b}$. Statistically significant differences between the test and control groups were detected before suturing $(p<0.001)$ (Table $1 a)$. When considering the six apico-coronal levels $\left(\mathrm{HT}_{0-5 \mathrm{~mm}}\right)$ as a whole, neither wound closure $(\mathrm{p}=0.891)$ nor the different GBR procedures ( $p=0.328$ ) induced any statistically significant change in HT (Table 1b).

The results for HT before and after suture and changes in HT at the 6 different apicocoronal levels $\left(\mathrm{HT}_{0-5 \mathrm{~mm}}\right)$ for the two GBR procedures are presented in Tables 2 and 3 and Figures 4 and 5.

The change in $\mathrm{HT}_{0 \mathrm{~mm}}$ was $-20.5 \pm 23.3 \%$ (SD) for the control group $(\mathrm{p}<0.001)$ and $-2.4 \pm 9.2 \%(S D)$ for the test group $(p=0.197)$. The changes in $\mathrm{HT}_{1-5 \mathrm{~mm}}$ ranged from $-7.4 \pm 17.1 \%(S D)$ to $+8.4 \pm 20.8 \%(S D)$ in the control group and from $-1.2 \pm$ $8.6 \%(\mathrm{SD})$ to $+12.0 \pm 15.3 \%(\mathrm{SD})$ in the test group.

For the control procedure, the reductions in $\mathrm{HT}_{0 \mathrm{~mm}}$ and $\mathrm{HT}_{1 \mathrm{~mm}}(\mathrm{p}<0.001$ and $\mathrm{p}=0.03$ respectively) were statistically significant. No significant changes in $\mathrm{HT}_{0 \mathrm{~mm}}(p=0.197)$ or $\mathrm{HT}_{1 \mathrm{~mm}}(\mathrm{p}=0.647)$ were observed for the test procedure.

The differences in changes in $\mathrm{HT}_{0 \mathrm{~mm}}$ between the control and test groups were statistically significant $(p=0.014)$. There were no significant differences between the two treatment approaches for $\mathrm{HT}_{1-5 \mathrm{~mm}}\left(\mathrm{HT}_{1 \mathrm{~mm}}, \mathrm{p}=0.106 ; \mathrm{HT}_{2 \mathrm{~mm}}, \mathrm{p}=0.748 ; \mathrm{HT}_{3 \mathrm{~mm}}, \mathrm{p}\right.$ $=0.257 ; \mathrm{HT}_{4 \mathrm{~mm}}, \mathrm{p}=0.789 ; \mathrm{HT}_{5 \mathrm{~mm}}, \mathrm{p}=0.100$ ) (Table 3).

Reductions of $28.0 \pm 11.9 \%$ (SD) in VT and $24.8 \pm 10.2 \%$ (SD) in 450-T were observed in the test group. Both differences were statistically significant $(p<0.001)$ (Table 4; Fig. 6).

In both treatment modalities, no void spaces $(0 / 20=0 \%)$ were detected within the augmented regions after wound closure.

\section{In vitro pig mandible study model reliability}

No statistically significant differences were detected between the "granulate + pins" group from the previous study (Mir-Mari et al 2015) and the control group in the present study, which used identical materials (particulate xenograft + collagen membrane + pins $)(p=0.942)$, either when comparing the treatments at the six 
different heights $\left(\mathrm{HT}_{0-5 \mathrm{~mm}}\right)$, or when comparing them before and after wound closure ( $\mathrm{p}$ $=0.757$ ), Table 5 .

Table 6 shows the absolute $(\mathrm{mm})$ and relative (\%) mean differences between the "granulate + pins" group in the previous study and the control group in the present study. No statistically significant differences were found at any of the six measurement heights $\left(\mathrm{HT}_{0-5 \mathrm{~mm}}\right)(\mathrm{p}=0.236-0.861)$ (Table 6$)$. These findings indicate that the model presents a high degree of reproducibility.

\section{DISCUSSION}

The present in vitro study demonstrated improved bone graft stability at the implant collar level when a soft-block bone substitute was added to a particulate xenograft. Moreover, the L-shaped soft-block bone substitute showed significant compression capability and adaptability to the bone defect without compromising horizontal regeneration stability.

The first part of the current research project detected between $-20 \%$ and $-40 \%$ horizontal thickness change at $\mathrm{HT}_{0 \mathrm{~mm}}$ and significant increases in graft stability in the middle and apical areas of the GBR (Mir-Mari et al. 2015). The use of fixation pins or a block bone substitute showed enhanced graft stability compared to the particulate xenograft alone. However, a $20 \%$ reduction was still found in the most coronal parts of the regeneration. In the present study, the change in $H T$ between $\mathrm{HT}_{0 \mathrm{~mm}}$ and $\mathrm{HT}_{5 \mathrm{~mm}}$ in the control group (particulate bone substitute + collagen membrane + pins) ranged from a $20.5 \%$ reduction at $\mathrm{HT}_{0 \mathrm{~mm}}$ to an $8.4 \%$ increase at $\mathrm{HT}_{5 \mathrm{~mm}}$. A recent animal study compared solid blocks of equine- and bovine-derived bone substitute materials with particulate bone grafts in combination with simultaneous implant placement for the regeneration of acute-type semi-saddle bone defects (Benic et al. 2015). The intraoperative horizontal thickness of the augmented regions measured $3 \mathrm{~mm}$ in all the groups. After wound closure and 4 months' healing for all the GBR procedures, less horizontal thickness of the augmented region was found at implant shoulder level (mean values: $0.6-1.7 \mathrm{~mm}$ ) in comparison to the level $3 \mathrm{~mm}$ apical to the implant shoulder (mean values: $2.2-2.8 \mathrm{~mm}$ ). In both studies, the solid blocks made of bovine xenograft performed better than the particulate xenograft as regards the horizontal stability of the augmented region, both during wound closure and during wound closure and also after 4 months of healing (Mir-Mari et al. 2015, Benic et al. 
2015). However, both studies reported dislocations of the solid bovine-derived blocks. These observations are in agreement with the findings of previous studies (Schwarz et al 2010 \& Bae et al 2014), which have reported handling and adaptation difficulties with solid type blocks.

In order to overcome any instability of the augmented region, the present study investigated the use of an L-shaped soft-block bone substitute. The change in $\mathrm{HT}_{0 \mathrm{~mm}}$ improved from $-20.5 \%$ to $-2.4 \%$ when the L-shaped soft block was applied. A higher mean displacement in the control group was observed at $\mathrm{HT}_{0 \mathrm{~mm}}$ and $\mathrm{HT}_{1 \mathrm{~mm}}$, with mean reductions of $0.6 \pm 0.5 \mathrm{~mm}$ and $0.3 \pm 0.5 \mathrm{~mm}$ respectively. In contrast, the test group only showed $0.1 \pm 0.4 \mathrm{~mm}$ and $0.0 \pm 0.4$ reductions at $\mathrm{HT}_{0 \mathrm{~mm}}$ and $\mathrm{HT}_{1 \mathrm{~mm}}$ respectively.

A decade ago, a soft-block bone substitute in which deproteinized bovine bone mineral (DBBM) particles were incorporated into a $10 \%$ collagen matrix was introduced in the context of ridge preservation (Nevins et al. 2003; Jung et al. 2004; Sculean et al. 2005; Araújo \& Lindhe 2009; Araujo et al. 2011). Due to its flexibility and adaptability, some authors have proposed its use for horizontal augmentation. A previous animal study (Schwarz et al. 2007) compared hydroxyapatite + beta tricalcium phosphate bone substitutes with soft-blocks of DBBM for simultaneous GBR in combination with implant placement. Although good results were reported with the collagen-coated bone mineral after a healing period of 1 - 9 weeks, the authors still noted some membrane dislocation and bone graft displacement in an apical direction.

According to previous studies, apical displacement of bone substitute is a common finding during and/or after wound closure in GBR procedures (Schwarz et al. 2007, Schwarz et al. 2010; Bae et al. 2014; Mir-Mari et al. 2015, Benic et al. 2015). The application of an L-shaped soft-block of DBBM demonstrated increased coronal stability at the implant collar level $\left(0.1 \pm 0.4 \mathrm{~mm}\right.$ reduction in $\left.\mathrm{HT}_{0 \mathrm{~mm}}\right)$. While the horizontal thickness remained stable, all the pressure was applied to the occlusal part of the softblock. As a result, the vertical thickness fell by $28 \%$ and the $45^{\circ}$ thickness by $24.8 \%$. The combination of the granular DBBM with a collagen matrix showed high compression capability and adaptability to the defect anatomy without compromising horizontal augmentation and tension-free wound closure. Additionally, no void spaces were detected in any of the 20 samples $(0 / 20 ; 0 \%)$, demonstrating the adaptability of the bone graft. 
The role of fixation pins should also be emphasized. As demonstrated in a previous publication (Mir-Mari et al. 2015), fixation pins substantially enhance graft stability. These authors described frequent block dislocation or rotation (0-35\%) when a hardblock bone substitute was used without pins. This is in agreement with a previous animal study where soft-blocks of DBBM were used in combination with collagen membranes without fixation to regenerate dehiscence type defects around dental implants (Schwarz et al. 2007). Membrane dislocation and apical graft displacements were frequently observed and, according to the authors, were attributed to poor adaptation of the bone graft at the implant surface.

Given the in vitro nature of the current investigation, no conclusions about bone regeneration can be drawn. However, a few comments should be made regarding expected bone formation properties with the L-shape technique. As demonstrated histologically in previous studies, xenograft bone blocks are associated with less new bone formation (Araújo et al 2002; De Santis et al. 2012, Schwarz et al 2008, Schwarz et al. 2010). Large dehiscence defects (Schwarz et al. 2010; Benic et al. 2015) and low compression of the graft (increased space between particles) (Romanos et al. 2015) may be some of the reasons, which could explain why graft particles become embedded in a fibrous tissue instead of forming new bone. Consequently, the combination of a granular bone substitute plus an additional layer of soft-block bone substitute aims to achieve a stable coagulum with high potential for bone regeneration around the implant surface while retaining as much volume as possible in the buccal and occlusal areas. In fact, connective tissue integration of the particles is expected to happen in the most external aspect of the GBR. Future research should analyse further the quality of tissue formation and the long-term stability of the volume achieved when using a combination of particulate and soft-block bone substitutes.

Finally, no statistically significant differences were detected between the "granulate + pins" treatment in the first part of the investigation (Mir-Mari et al. 2015) and the repetition of the same treatment in the second part $(p>0.05)$. Therefore, the present study has proved the reliability and reproducibility of the pig mandible in vitro study model for analysing immediate GBR stability. Consequently, this in vitro model could be used to check for other GBR characteristics associated with material stability.

The in vitro set-up allowed for a standardization of the procedures under investigation (flap design and tension, defect size, amount of bone substitutes...). On the other hand, only partial simulation of the clinical scenario of the GBR peri-implant defects 
could be achieved. In fact, blood clot formation might enhance stability of the bone substitute. However, even though coagulation plays a role in the early healing, it cannot prevent the displacement of the bone substitute during wound closure.

Technical differences between the two treatment approaches tested may be considered a possible limitation of the present study. In the particulate bone substitute group, GBR was only applied buccally, while in the L-shape group the material was applied to both the buccal and occlusal regions. It is important to stress that the main objective of this study was to compare two different GBR approaches applied in the way they would be used in a real clinical scenario. A technical modification to make the comparisons more homogeneous would not be appropriate for this purpose. In addition, it is important to bear in mind that only the intra-group differences within the test and control group were used for inter-group comparisons between them. Every site was treated once with each one of the two GBR procedures under investigation. This allowed eliminating the confounding effects related to flap characteristics and defect morphology. Blinding at the time of suturing was not possible. Finally, it should also be noted that as this series of two papers is the first in the literature to address immediate bone regeneration stability, there is a lack of comparable information on methodology, results and conclusions.

\section{CONCLUSIONS}

Within the limitations of the present in vitro study, it can be concluded that for GBR of peri-implant bone defects:

- The use of an L-shaped soft-block bone substitute added to a particulate xenograft in combination with a collagen membrane and fixation pins enhanced the horizontal volume stability of the augmented region during flap closure.

- The present in vitro investigation model appears to be reliable for assessing the primary stability of biomaterials used for GBR. 


\section{Acknowledgements}

The researchers gratefully acknowledge the assistance of Malgorzata Roos, Ph.D. (Department of Biostatistics, University of Zurich, Zurich, Switzerland) and Dr. Caroline Lustenberger (Clinic of Fixed and Removable Prosthodontics and Dental Material Science, Center of Dental Medicine, University of Zurich, Switzerland) for assistance in analysing the data. This study received support from the Clinic of Fixed and Removable Prosthodontics and Dental Material Science, Center of Dental Medicine, University of Zurich, Switzerland. The implants were kindly provided by DENTSPLY Implants, Mannheim, Germany. Mary Georgina Hardinge provided English language editing assistance. 


\section{TABLE LEGENDS}

Table 1. (a) Results of two-factor repeated-measures ANOVA for horizontal thickness of the augmented region before suturing (baseline) and (b) Results of two- and threefactor repeated-measures ANOVA for horizontal thickness of the augmented region after suturing

Table 2. Horizontal thickness of the augmented region (HT) and changes in $H T$ at different apico-coronal levels for procedures (a) control (particulate + collagen membrane + pins) and (b) test (particulate + L-shape + collagen membrane + pins)

Table 2_EP for electronic publication (extended version of table 2 including mean, $95 \% \mathrm{CI}$, median, minimum and maximum values) Horizontal thickness of the augmented region (HT) and changes in $\mathrm{HT}$ at different apico-coronal levels for procedures (a) control (particulate + collagen membrane + pins) and (b) test (particulate + L-shape + collagen membrane + pins)

Table 3. Changes in horizontal thickness of the augmented region for the different treatment procedures and results of repeated-measures ANOVA

Table 3_EP for electronic publication (extended version of table 2 including mean, $95 \% \mathrm{CI}$, median, minimum and maximum values). Changes in horizontal thickness of the augmented region for the different treatment procedures and results of repeatedmeasures ANOVA

Table 4. Mean values and changes in vertical thickness and $45^{\circ}$ thickness of the augmented region in the test procedure (particulate + L-shape + collagen membrane + pins) and results of statistical analysis.

Table 4_EP for electronic publication (extended version of table 2 including mean, $95 \% \mathrm{CI}$, median, minimum and maximum values). Mean values and changes in vertical thickness and $45^{\circ}$ thickness of the augmented region in the test procedure (particulate + L-shape + collagen membrane + pins) and results of statistical analysis. 
Table 5. Results of three-factor repeated-measures ANOVA for horizontal thickness of the augmented region in the "granulate + pins" (particulate + collagen membrane + pins) groups from the first and second study

Table 6. Horizontal thickness of the augmented region (HT) and changes in $H T$ at different apico-coronal levels for (a) particulate + collagen membrane + pins treatment $\left(1^{\text {st }}\right.$ study) and (b) particulate + collagen membrane + pins treatment ( $2^{\text {nd }}$ study)

Table 6_EP for electronic publication (extended version of table 2 including mean, 95\% CI, median, minimum and maximum values). Horizontal thickness of the augmented region (HT) and changes in HT at different apico-coronal levels for (a) particulate + collagen membrane + pins treatment $\left(1^{\text {st }}\right.$ study) and (b) particulate + collagen membrane + pins treatment $\left(2^{\text {nd }}\right.$ study) 


\section{FIGURE LEGENDS}

Figure 1. (a) Buccal and (b) occlusal view of the experimental peri-implant bone defect

Figure 2. (a) Particulate xenograft applied in the particulate treatment modality; (b) L-shaped soft-block xenograft used for the L-shape treatment modality; (c) buccal and (d) occlusal view of the L-shape treatment procedure; (e) collagen membrane stabilized by two titanium pins; (f) buccal view after suturing

Figure 3. Bucco-oral CBCT reconstructions with the measurements of the augmented regions (dimensions: HTO mm-HT5 mm, VT and 45-T): (a) particulate and (b) L-shape treatments before suturing; (c) particulate and (d) L-shape treatments after suturing

Figure 4. Bar plots representing the horizontal thicknesses of the augmented regions at different apico-coronal levels (HTO mm-HT5 mm) before and after suturing in (a) control group (particulate + collagen membrane + pins) and (b) test group (particulate + L-shaped soft-block + collagen membrane + pins). Error lines represent +/- 2 standard deviations

Figure 5. Box plots representing the changes in horizontal thickness of the augmented regions during suturing for particulate (control) and L-shape (test) treatment procedures (a) in $\mathrm{mm}$ and (b) in \%

Figure 6. Bar plots representing the vertical thicknesses and $45^{\circ}$ thicknesses of the augmented regions in the test group (particulate + soft-block + collagen membrane + pins). Error lines represent $+/-2$ standard deviations 


\section{REFERENCES}

Araújo, M.G., Sonohara, M., Hayacibara, R., Cardaropoli, G. \& Lindhe, J. (2002) Lateral ridge augmentation by the use of grafts comprised of autologous bone or a biomaterial. An experiment in the dog. Journal of Clinical Periodontology 29:11221131.

Araújo, M.G. \& Lindhe, J. (2009) Ridge preservation with the use of Bio-Oss collagen: A 6-month study in the dog. Clinical Oral Implants Research 20:433-440.

Araújo, M.G., Linder, E. \& Lindhe, J. (2011) Bio-Oss collagen in the buccal gap at immediate implants: a 6-month study in the dog. Clinical Oral Implants Research 22:1-8.

Bae, S.Y., Park, J.C., Shin, H.S., Lee, Y.K., Choi, S.H. \& Jung, U.W. (2014) Tomographic and histometric analysis of autogenous bone block and synthetic hydroxyapatite block grafts without rigid fixation on rabbit calvaria. Journal of Periodontal \& Implant Science 44:251-258.

Benic, G.I., Jung, R.E., Siegenthaler, D.W. \& Hämmerle, C.H.F. (2009) Clinical and radiographic comparison of implants in regenerated or native bone: 5-year results. Clinical Oral Implants Research 20: 507-513.

Benic, G.I, Sancho-Puchades, M., Jung, R.E., Deyhle, H. \& Hämmerle, C.H. (2013) In vitro assessment of artifacts induced by titanium dental implants in cone beam computed tomography. Clinical Oral Implants Research 24:378-383.

Benic, G.I. \& Hammerle, C.H. (2014) Horizontal bone augmentation by means of guided bone regeneration. Periodontology 2000 66:13-40.

Benic, G.I., Thoma, D.S., Muñoz, F., Sanz-Martin, I., Jung, R.E. \& Hämmerle, CH. (2015) Guided bone regeneration of peri-implant defects with particulated and block xenogenic bone substitutes. Clinical Oral Implants Research [Epub ahead of print]

Carpio, L., Loza, J., Lynch, S. \& Genco, R. (2000) Guided bone regeneration around endosseous implants with anorganic bovine bone mineral. A randomized controlled trial comparing bioabsorbable versus non-resorbable barriers. Journal of Periodontology 71:1743-1749. 
Chiapasco, M. \& Zaniboni, M. (2009) Clinical outcomes of GBR procedures to correct peri-implant dehiscences and fenestrations: a systematic review. Clinical Oral Implants Research 20(Suppl 4):113-123.

Dahlin C, Lekholm U, Becker W, Becker B, Higuchi K, Callens A, et al. (1995) Treatment of fenestration and dehiscence bone defects around oral implants using the guided tissue regeneration technique: a prospective multicenter study. The International journal of oral \& maxillofacial implants 10:312-318.

De Santis, E., Lang, N.P., Scala, A., Vigano, P., Salata, L.A. \& Botticelli, D. (2012) Healing outcomes at implants installed in grafted sites: an experimental study in dogs. Clinical Oral Implants Research 23:340-350.

Faul, F., Erdfelder, E., Lang, A.-G., Buchner, A. (2007). G*Power 3: A flexible statistical power analysis program for the social, behavioral, and biomedical sciences. Behavior Research Methods 39: 175-191.

Faul, F., Erdfelder, E., Buchner, A., Lang, A.-G. (2009). Statistical power analyses using G*Power 3.1: Tests for correlation and regression analyses. Behavior Research Methods 41: 1149-1160.

Fugazzotto PA. (1997) Success and failure rates of osseointegrated implants in function in regenerated bone for 6 to 51 months: a preliminary report. The International journal of oral \& maxillofacial implants 12:17-24.

Grunder, U., Gracis, S. \& Capelli, M. (2005) Influence of the 3-D bone-to-implant relationship on esthetics. The International Journal of Periodontics and Restorative Dentistry 25:113-119.

Jung, R.E., Siegenthaler, D.W. \& Hämmerle, C.H. (2004) Postextraction tissue management: a soft tissue punch technique. The International Journal of Periodontics and Restorative Dentistry 24:545-553.

Jung, R.E., Sailer, I., Hämmerle, C.H., Attin, T. \& Schmidlin, P. (2007) In vitro color changes of soft tissues caused by restorative materials. The International Journal of Periodontics and Restorative Dentistry 27:251-257.

Jung, R.E., Fenner, N., Zitzmann, N.U. \& Hammerle, C.H. (2013) Long-term outcome of implants placed with guided bone regeneration (GBR) using resorbable and non- 
resorbable membranes after 12 to 14 years. Clinical Oral Implants Research 24: 10651073.

Jung, R.E., Benic, G.I., Scherrer, D. \& Hämmerle, CH. (2015) Cone beam computed tomography evaluation of regenerated buccal bone 5 years after simultaneous implant placement and guided bone regeneration procedures--a randomized, controlled clinical trial. Clinical Oral Implants Research 26:28-34.

Jung, U.W., Lee, J.S., Lee, G., Lee, I.K., Hwang, J.W., Kim, M.S. et al. (2013) Role of collagen membrane in lateral onlay grafting with bovine hydroxyapatite incorporated with collagen matrix in dogs. Journal of Periodontal and Implant Science 43:64-71.

Lorenzoni, M., Pertl, C., Keil, C. \& Wegscheider, W.A. (1998) Treatment of peri-implant defects with guided bone regeneration: a comparative clinical study with various membranes and bone grafts. The International journal of oral \& maxillofacial implants 13:639-646.

Mir-Mari, J., Wui, H., Jung, R.E., Hämmerle, C.H. \& Benic, G.I. (2015) Influence of blinded wound closure on the volume stability of different GBR materials: an in vitro cone-beam computed tomographic examination. Clinical Oral Implants Research [Epub ahead of print]

Nevins, M.L., Camelo, M., Lynch, S.E., Schenk, R.K., Nevins, M. (2003) Evaluation of periodontal regeneration following grafting intrabony defects with bio-oss collagen: a human histologic report. International Journal of Periodontics and Restorative Dentistry 23:9-17.

Schwarz, F., Herten, M., Ferrari, D., Wieland, M., Schmitz, L., Engelhardt, E. \& Becker, J. (2007) Guided bone regeneration at dehiscence-type defects using biphasic hydroxyapatite + beta tricalcium phosphate (Bone Ceramic) or a collagen-coated natural bone mineral (BioOss Collagen): an immunohistochemical study in dogs. International Journal of Oral and Maxillofacial Surgery 36:1198-1206.

Schwarz, F., Rothamel, D., Herten, M., Ferrari, D., Sager, M. \& Becker, J. (2008) Lateral ridge augmentation using particulated or block bone substitutes biocoated with rhGDF-5 and rhBMP-2: an immunohistochemical study in dogs. Clinical Oral Implants Research 19:642-652. 
Schwarz, F., Ferrari, D., Balic, E., Buser, D., Becker, J. \& Sager, M. (2010) Lateral ridge augmentation using equine- and bovine-derived cancellous bone blocks: a feasibility study in dogs. Clinical Oral Implants Research 21:904-912.

Sculean, A., Chiantella, G.C., Windisch, P., Arweiler, N.B., Brecx, M. \& Gera, I. (2005) Healing of intra-bony defects following treatment with a composite bovine-derived xenograft (Bio-Oss Collagen) in combination with a collagen membrane (Bio-Gide PERIO). Journal of Clinical Periodontology 32:720-724.

von Arx, T., Cochran, D.L., Hermann, J.S., Schenk, R.K. \& Buser, D. (2001) Lateral ridge augmentation using different bone fillers and barrier membrane application. A histologic and histomorphometric pilot study in the canine mandible. Clinical oral implants research 12:260-269.

Zecha, P.J., Schortinghuis, J., van der Wal, J.E., Nagursky, H., van den Broek, KC., Sauerbier, S., et al. (2011) Applicability of equine hydroxyapatite collagen (eHAC) bone blocks for lateral augmentation of the alveolar crest. A histological and histomorphometric analysis in rats. International Journal of Oral \& Maxillofacial Surgery 40:533-542.

Zitzmann, N.U, Naef, R. \& Scharer, P. (1997) Resorbable versus nonresorbable membranes in combination with Bio-Oss for guided bone regeneration. The International journal of oral \& maxillofacial implants 12:844-852.

Zitzmann, N.U., Schärer, P. \& Marinello, C.P. (1999) Factors influencing the success of GBR. Smoking, timing of implant placement, implant location, bone quality and provisional restoration. Journal of Clinical Periodontology 26:673-682.

Zumstein, T., Billstrom, C. \& Sennerby, L. (2012) A 4- to 5-Year Retrospective Clinical and Radiographic Study of Neoss Implants Placed with or without GBR Procedures. Clinical Implant Dentistry and Related Research 14: 480-490. 


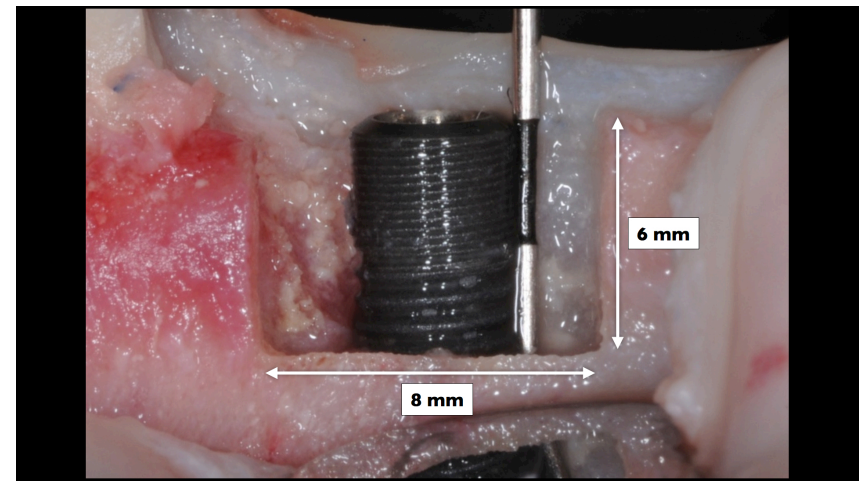

Figure 1a)

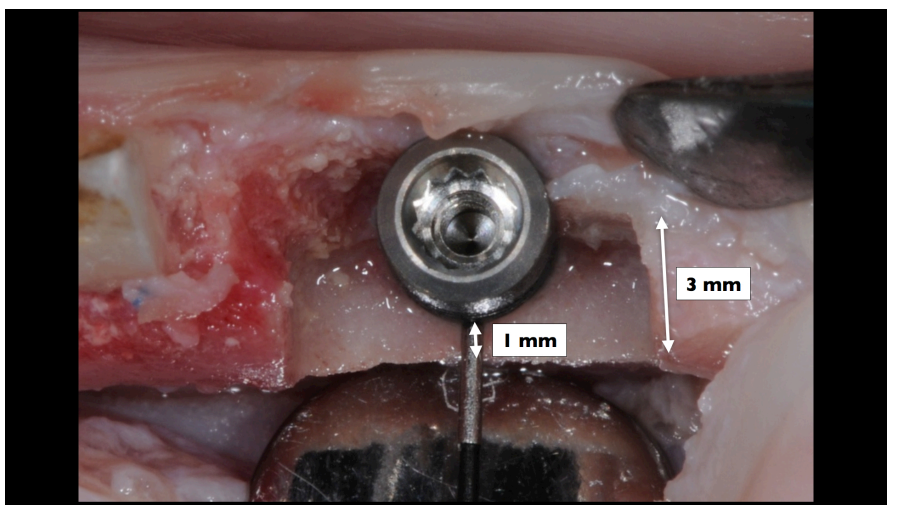

Figure $1 b$ )

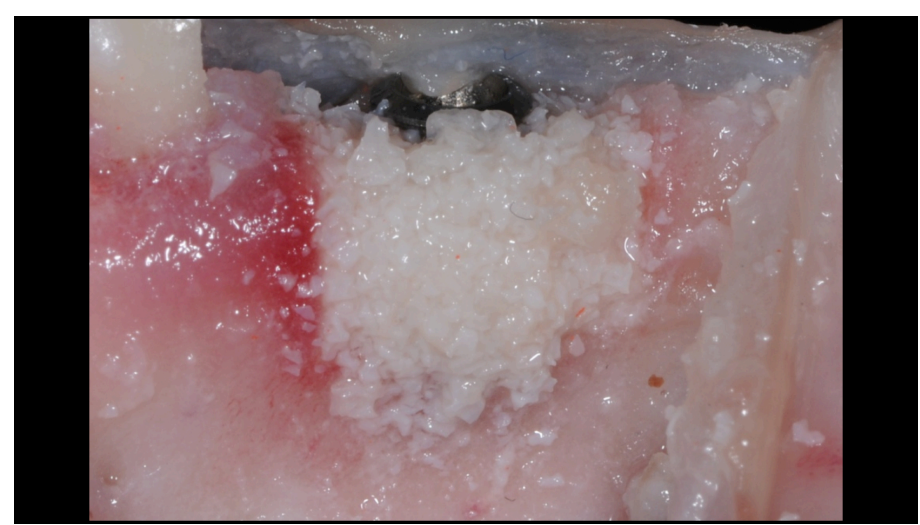

Figure 2a)

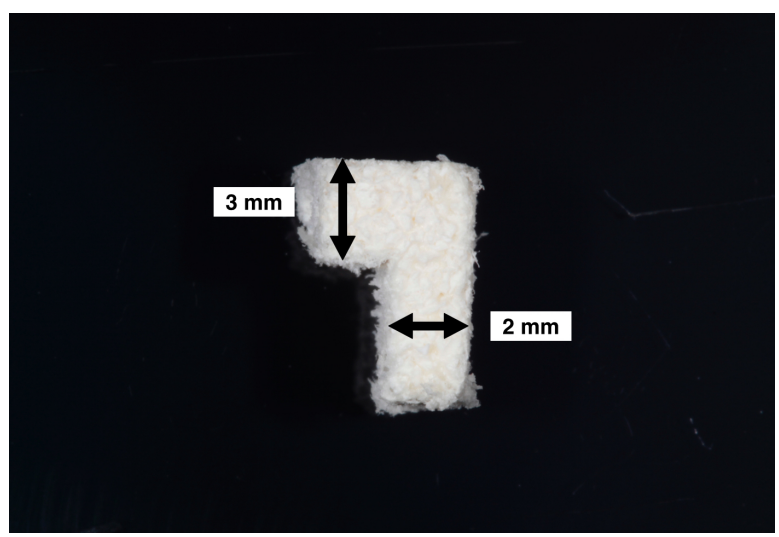

Figure $2 b$ ) 


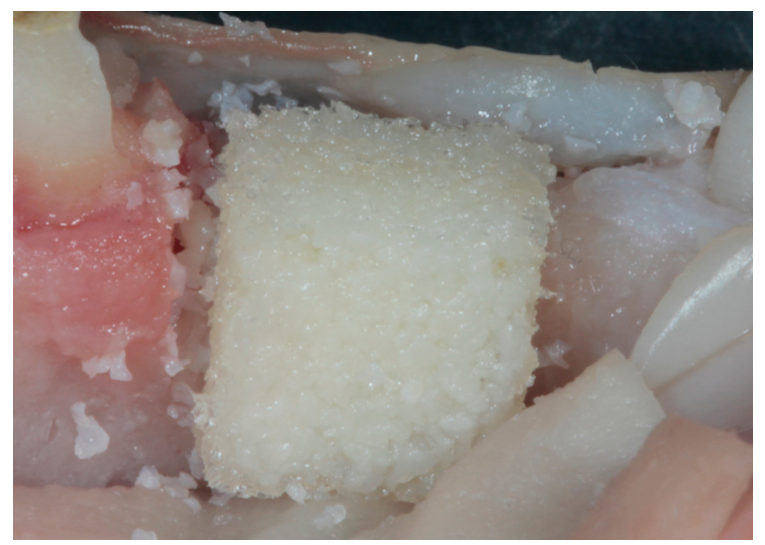

Figure 2c)

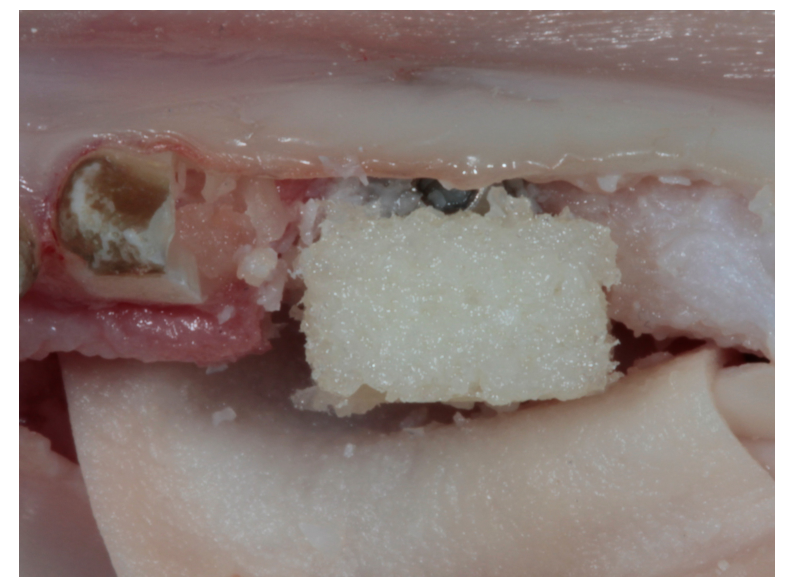

Figur 2d)

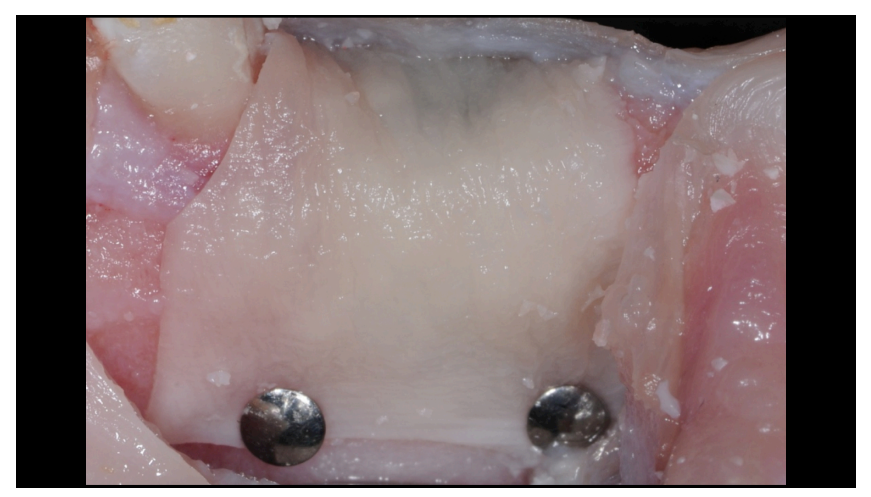

Figure 2e)

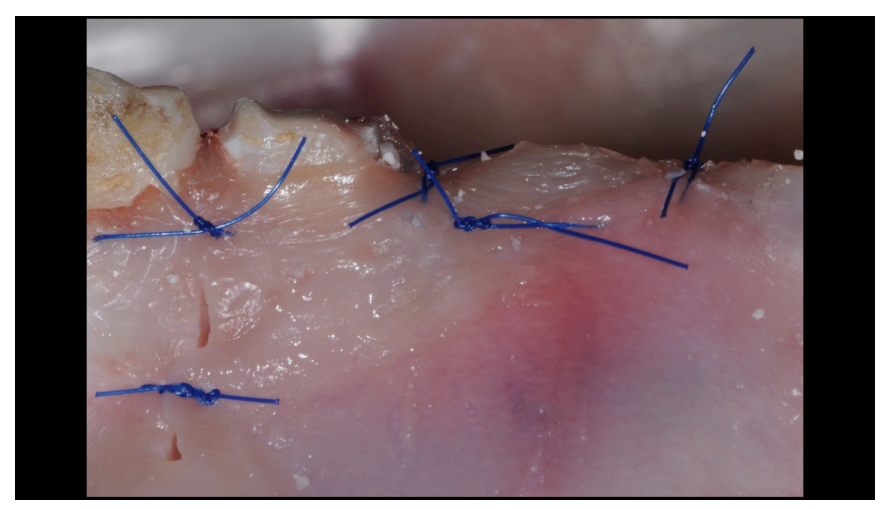

Figure 2f) 


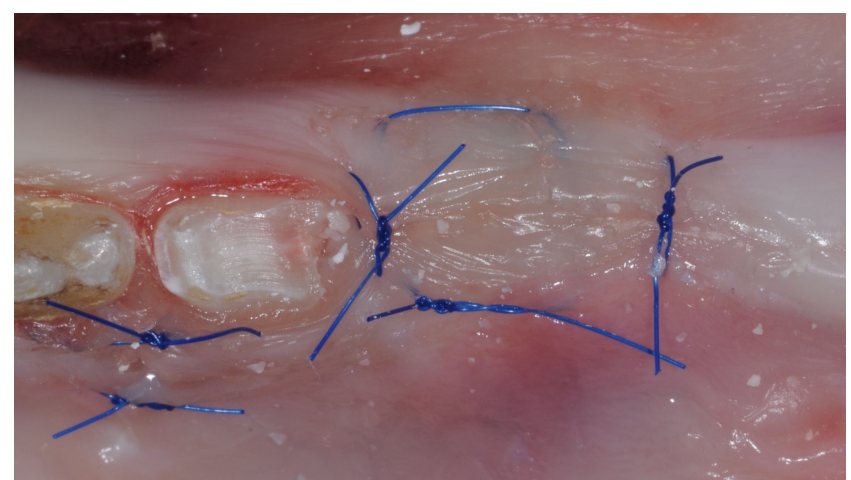

Figure 2g)

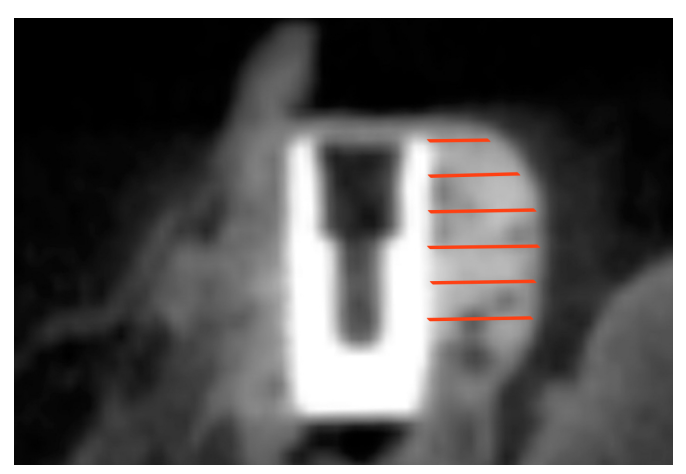

Figure 3a)

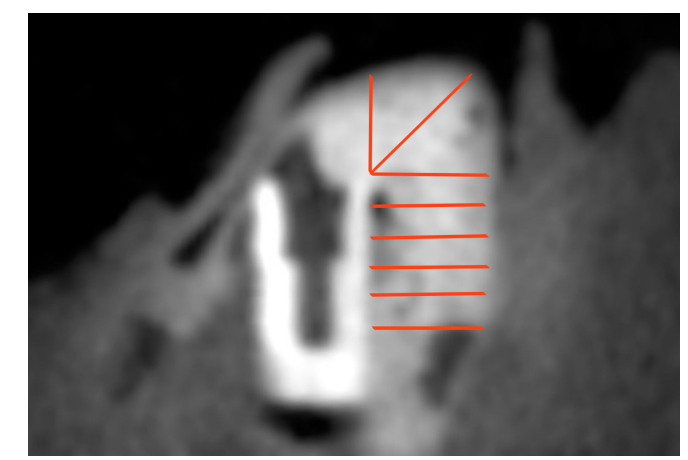

Figure $3 b$ )

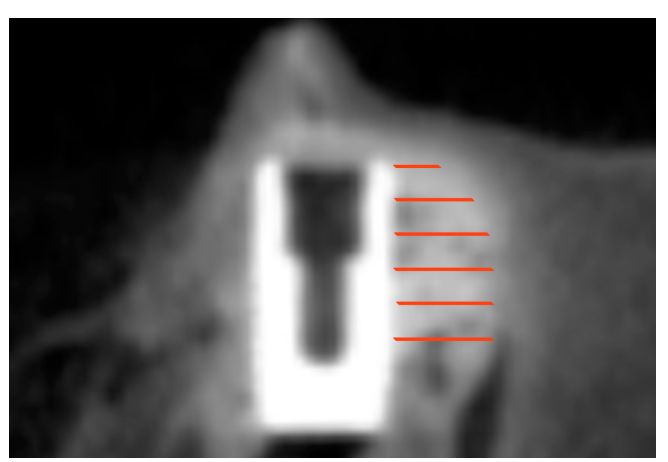

Figure 3c) 


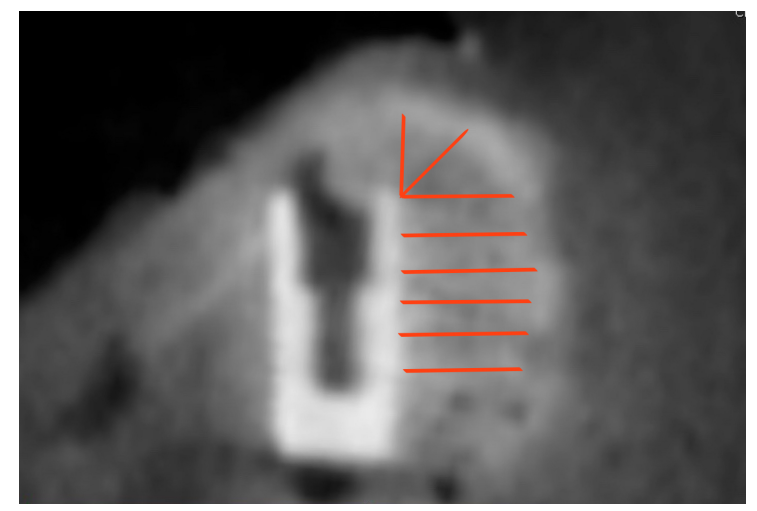

Figure 3d)

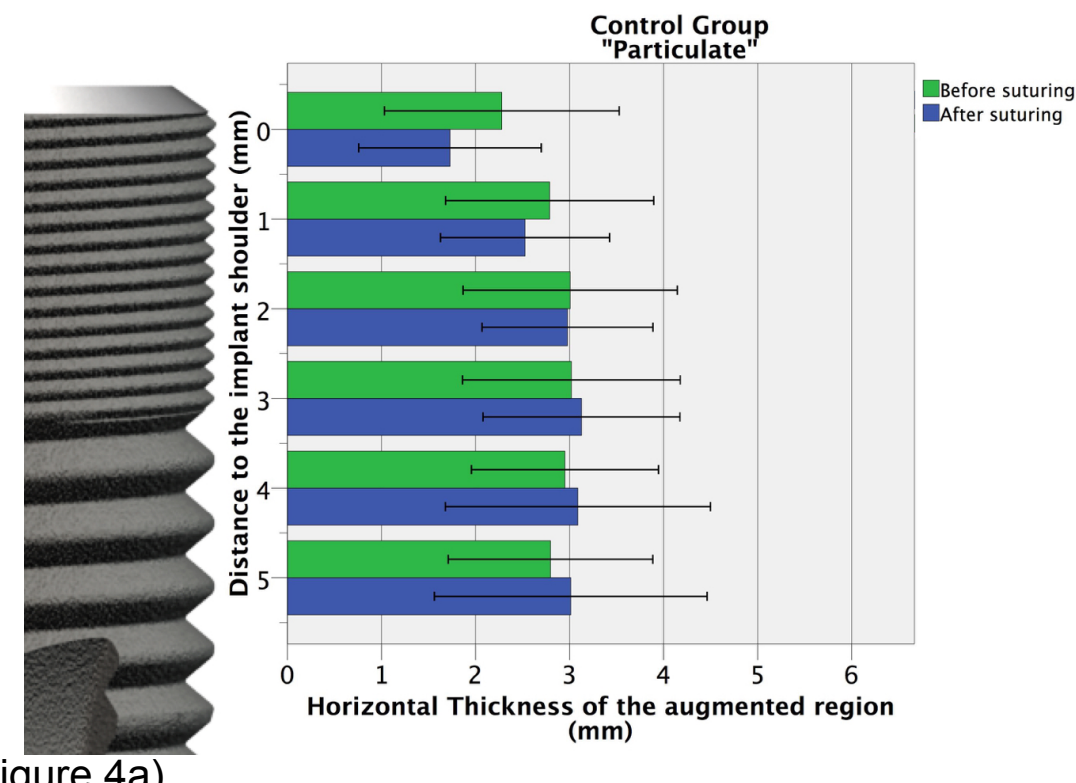

Figure 4a)

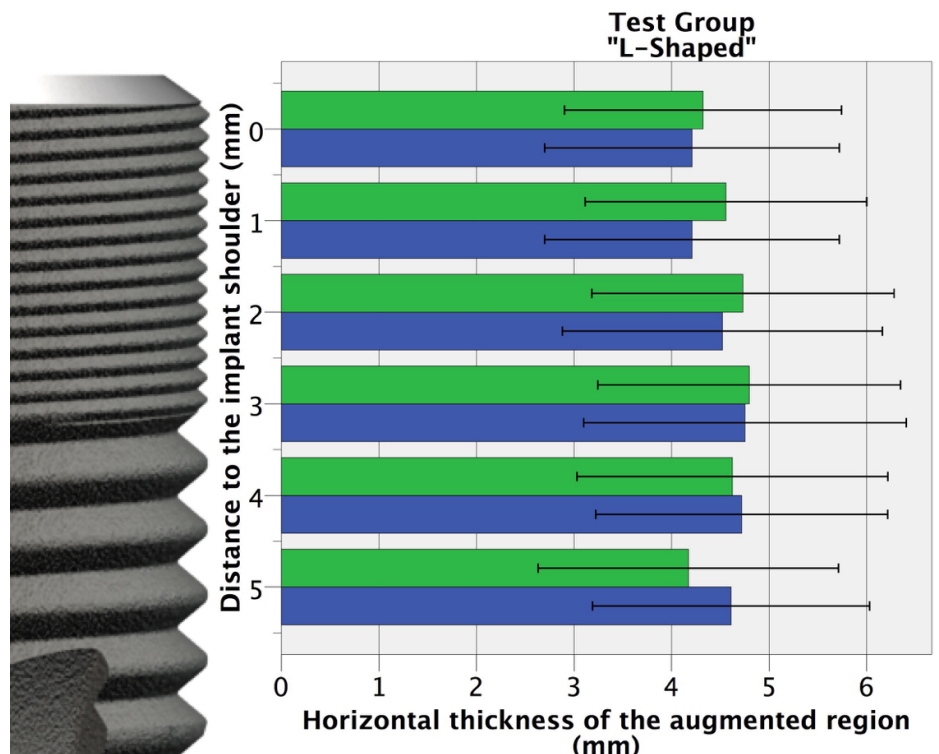

(mm)

Figure $4 b$ ) 


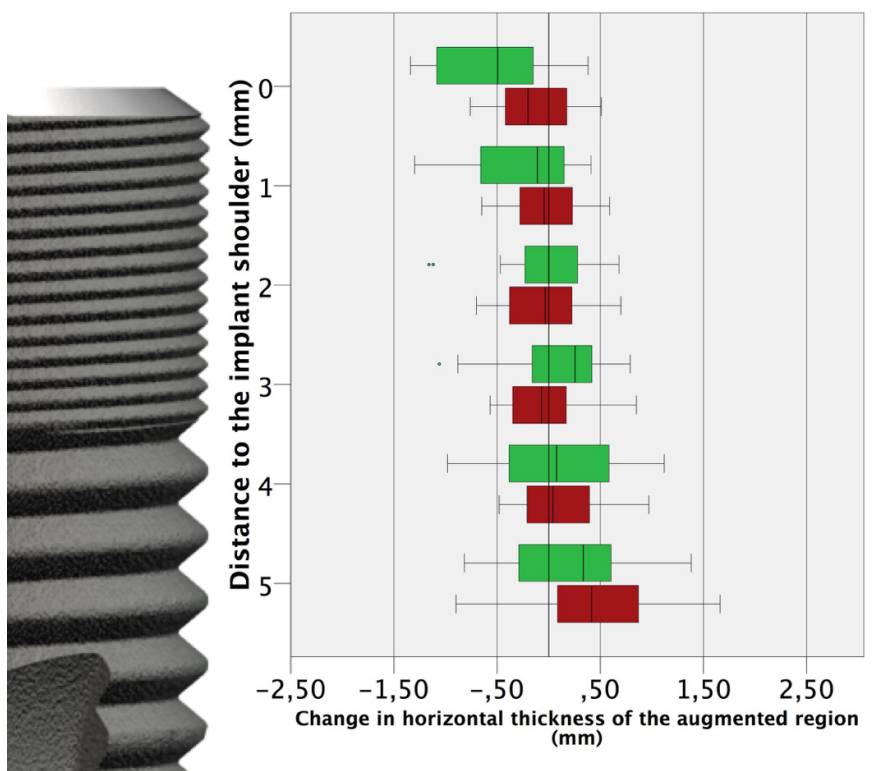

Treatment

modality

Control

-Test

Figure 5a)
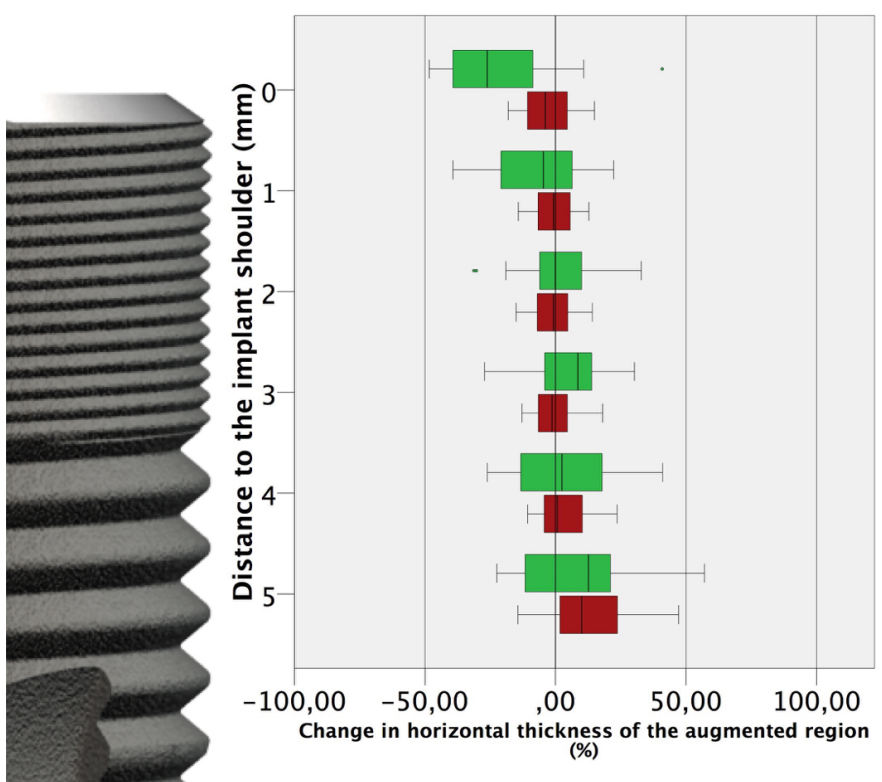

Treatment modality

Control

Test

Figure $5 b$ ) 


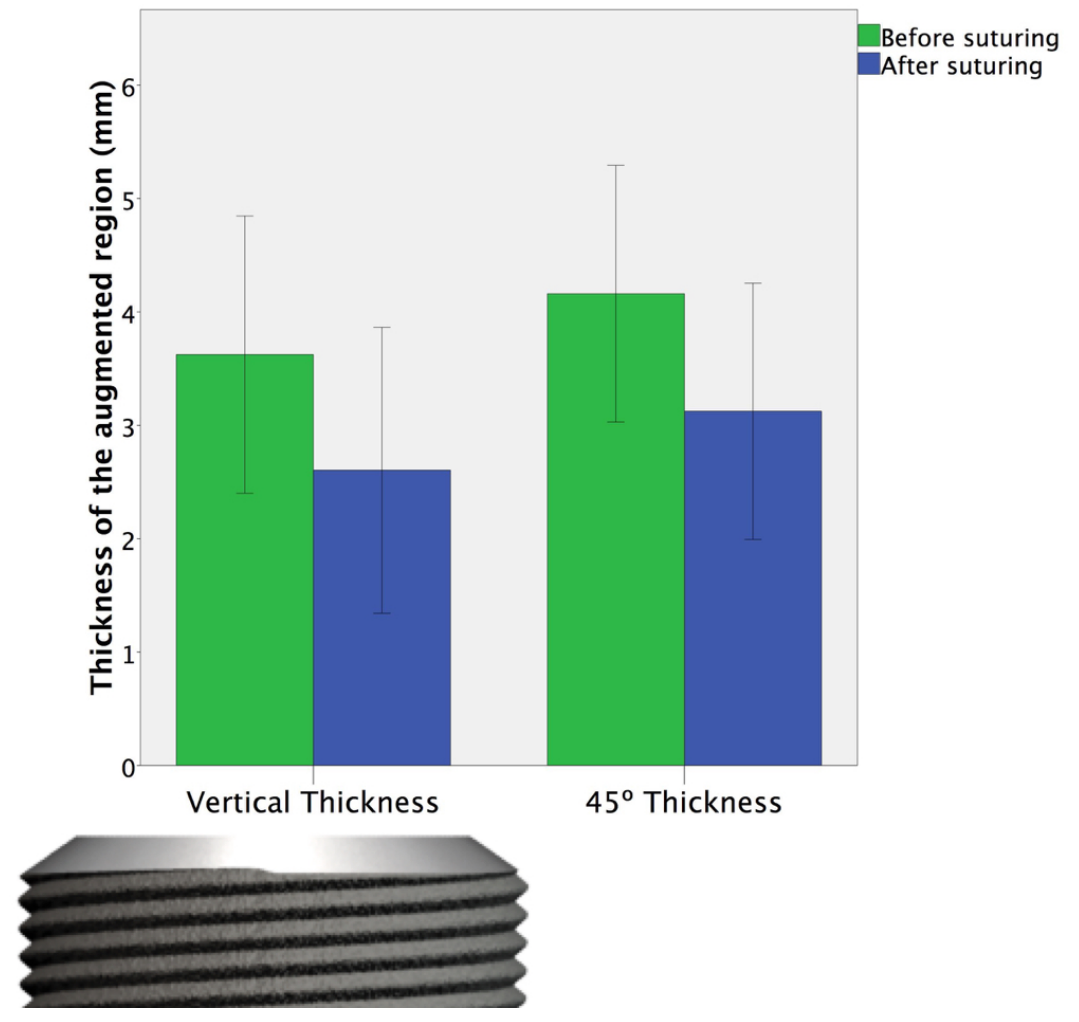

Figure 6 


\begin{tabular}{|c|c|c|c|c|}
\hline Factor(s) & $\begin{array}{l}\text { Mauchly's } \\
\text { sphericity }\end{array}$ & $\mathrm{F}$ & df & $P$-value* \\
\hline \multicolumn{5}{|l|}{ (a) } \\
\hline (1) Treatment modality§ & 1.00 & 148.372 & 1 & $<0.001 \dagger$ \\
\hline (2) Apico-coronal level & $<0.001$ & 20.724 & 1.559 & $<0.001 \uparrow$ \\
\hline $\begin{array}{l}\text { (1) } \times(2) \\
\text { (b) }\end{array}$ & 0.009 & 12.755 & 2.400 & $<0.001 \dagger$ \\
\hline (1) Treatment modality§ & 1.000 & 245.144 & 1 & $<0.001 \uparrow$ \\
\hline (2) Apico-coronal level $\ddagger$ & $<0.001$ & 43.073 & 1.379 & $<0.001 \dagger$ \\
\hline (3) Suturing & 1.000 & 0.019 & 1.000 & 0.891 \\
\hline$(1) \times(2)$ & 0.003 & 27.396 & 1.621 & $<0.001 \uparrow$ \\
\hline$(1) \times(3)$ & 1.000 & 1.009 & 1.000 & 0.328 \\
\hline$(2) \times(3)$ & 0.001 & 13.781 & 1.547 & $<0.001 \dagger$ \\
\hline (1) $\times(2) \times(3)$ & 0.015 & 5.458 & 2.065 & 0.08 \\
\hline \multicolumn{5}{|c|}{$\begin{array}{l}\text { (a): (1), Treatment modality; (2), Apico-coronal level; }(3) \times \text {, interaction between the factors; F, F-test; } \\
\text { df, degrees of freedom. } \\
\text { (b): (1), Treatment modality; (2), Apico-coronal level; (3), Suturing; } x \text {, interactions between the fac- } \\
\text { tors. F, F-test; df, degrees of freedom. } \\
\text { *Results of repeated-measures ANOVA with Greenhouse-Geisser correction. } \\
\dagger \text { Statistically significant. } \\
\vdots 0-5 \text { mm apical to the implant shoulder. } \\
\text { §GBR procedures. }\end{array}$} \\
\hline
\end{tabular}

\section{Table 1}




\begin{tabular}{|c|c|c|c|c|c|c|}
\hline \multirow[b]{2}{*}{ Treatment modality } & \multirow[b]{2}{*}{ Parameter } & \multirow{2}{*}{$\frac{\text { Before suturing }(\mathrm{mm})}{\text { Mean } \pm \text { SD }[95 \% \mathrm{Cl}]}$} & \multirow[t]{2}{*}{ After suturing $(\mathrm{mm})$} & \multirow[t]{2}{*}{ Change $(\mathrm{mm})$} & \multirow[t]{2}{*}{ Change (\%) } & \multirow[b]{2}{*}{$P$-value* } \\
\hline & & & & & & \\
\hline \multicolumn{7}{|c|}{ (a) Control (particulate) $(n=20)$} \\
\hline $\mathrm{HT}_{0} \mathrm{~mm}$ & & $2.3 \pm 0.6[2.0 ; 2.6]$ & $1.7 \pm 0.5[1.5 ; 2.0]$ & $-0.6 \pm 0.5[-0.8 ;-0.3]$ & $-20.5 \pm 23.2[-31.4 ;-9.7]$ & $<0.001 \dagger$ \\
\hline $\mathrm{HT}_{1} \mathrm{~mm}$ & & $2.8 \pm 0.6[2.5 ; 3.0]$ & $2.5 \pm 0.5[2.3 ; 2.7]$ & $-0.3 \pm 0.5[-0.5 ;-0.0]$ & $-7.4 \pm 17.1[-15.4 ; 0.6]$ & $0.03 \dagger$ \\
\hline $\mathrm{HT}_{2} \mathrm{~mm}$ & & $3.0 \pm 0.6[2.7 ; 3.2]$ & $3.0 \pm 0.5[2.8 ; 3.2]$ & $-0.0 \pm 0.5[-0.3 ; 0.2]$ & $1.0 \pm 16.8[-6.8 ; 8.9]$ & 0.8 \\
\hline $\mathrm{HT}_{3} \mathrm{~mm}$ & & $3.0 \pm 0.6[2.7 ; 3.3]$ & $3.1 \pm 0.5[2.9 ; 3.4]$ & $0.1 \pm 0.5[-0.1 ; 0.3]$ & $5.3 \pm 16.3[-2.4 ; 12.9]$ & 0.346 \\
\hline $\mathrm{HT}_{4} \mathrm{~mm}$ & & $3.0 \pm 0.5[2.7 ; 3.2]$ & $3.1 \pm 0.7[2.8 ; 3.4]$ & $0.1 \pm 0.6[-0.1 ; 0.4]$ & $5.2 \pm 20.0[-4.2 ; 14.6]$ & 0.314 \\
\hline $\mathrm{HT}_{5} \mathrm{~mm}$ & & $2.8 \pm 0.5[2.5 ; 3.1]$ & $3.0 \pm 0.7[2.7 ; 3.4]$ & $0.2 \pm 0.6[-0.1 ; 0.5]$ & $8.4 \pm 20.8[-1.3 ; 18.2]$ & 0.123 \\
\hline \multicolumn{7}{|c|}{ (b) Test (L-shaped) $(n=20)$} \\
\hline $\mathrm{HT}_{0 \mathrm{~mm}}$ & & $4.3 \pm 0.7[4.0 ; 4.7]$ & $4.2 \pm 0.8[3.9 ; 4.6]$ & $-0.1 \pm 0.4[-0.3 ;-0.1]$ & $-2.4 \pm 9.2[-6.7 ; 1.9]$ & 0.197 \\
\hline $\mathrm{HT}_{1} \mathrm{~mm}$ & & $4.6 \pm 0.7[4.2 ; 4.9]$ & $4.5 \pm 0.8[4.1 ; 4.9]$ & $-0.0 \pm 0.4[-0.2 ; 0.1]$ & $-0.8 \pm 7.9[-4.5 ; 2.8]$ & 0.647 \\
\hline $\mathrm{HT}_{2} \mathrm{~mm}$ & & $4.7 \pm 0.8[4.4 ; 5.1]$ & $4.7 \pm 0.8[4.3 ; 5.1]$ & $-0.1 \pm 0.4[-0.3 ; 0.1]$ & $-1.2 \pm 8.6[-5.3 ; 2.8]$ & 0.462 \\
\hline $\mathrm{HT}_{3} \mathrm{~mm}$ & & $4.8 \pm 0.8[4.4 ; 5.2]$ & $4.8 \pm 0.8[4.4 ; 5.1]$ & $-0.0 \pm 0.4[-0.2 ; 0.1]$ & $-0.8 \pm 7.8[-4.4 ; 2.9]$ & 0.607 \\
\hline $\mathrm{HT}_{4} \mathrm{~mm}$ & & $4.6 \pm 0.8[4.3 ; 5.0]$ & $4.7 \pm 0.7[4.4 ; 5.1]$ & $0.1 \pm 0.4[-0.1 ; 0.3]$ & $2.7 \pm 9.6[-1.8 ; 7.2]$ & 0.311 \\
\hline $\mathrm{HT}_{5} \mathrm{~mm}$ & & $4.2 \pm 0.8[3.8 ; 4.5]$ & $4.6 \pm 0.7[4.3 ; 4.9]$ & $0.4 \pm 0.6[0.1 ; 0.7]$ & $12.0 \pm 15.3[4.8 ; 19.1]$ & 0.005 \\
\hline
\end{tabular}

Table 2 


\begin{tabular}{|c|c|c|c|c|c|}
\hline & \multicolumn{2}{|l|}{ Change (mm) } & \multicolumn{2}{|l|}{ Change $(\%)$} & \multirow{3}{*}{ Statistical analysis* } \\
\hline & Particulate & L-shaped & Particulate & L-shaped & \\
\hline & \multicolumn{4}{|l|}{ Mean \pm SD $[95 \% \mathrm{CI}]$} & \\
\hline $\mathrm{HT}_{0} \mathrm{~mm}$ & $-0.6 \pm 0.5[-0.8 ;-0.3]$ & $-0.1 \pm 0.4[-0.3 ;-0.1]$ & $-20.5 \pm 23.2[-31.4 ;-9.7]$ & $-2.4 \pm 9.2[-6.7 ; 1.9]$ & $P$ vs $L: P=0.014 \dagger$ \\
\hline $\mathrm{HT}_{1} \mathrm{~mm}$ & $-0.3 \pm 0.5[-0.5 ;-0.0]$ & $-0.0 \pm 0.4[-0.2 ; 0.1]$ & $-7.4 \pm 17.1[-15.4 ; 0.6]$ & $-0.8 \pm 7.9[-4.5 ; 2.8]$ & $P$ vs $L: P=0.106$ \\
\hline $\mathrm{HT}_{2} \mathrm{~mm}$ & $-0.0 \pm 0.5[-0.3 ; 0.2]$ & $-0.1 \pm 0.4[-0.3 ; 0.1]$ & $1.0 \pm 16.8[-6.8 ; 8.9]$ & $-1.2 \pm 8.6[-5.3 ; 2.8]$ & $P$ vs $L: P=0.748$ \\
\hline $\mathrm{HT}_{3} \mathrm{~mm}$ & $0.1 \pm 0.5[-0.1 ; 0.3]$ & $-0.0 \pm 0.4[-0.2 ; 0.1]$ & $5.3 \pm 16.3[-2.4 ; 12.9]$ & $-0.8 \pm 7.8[-4.4 ; 2.9]$ & $P$ vs $L: P=0.257$ \\
\hline $\mathrm{HT}_{4} \mathrm{~mm}$ & $0.1 \pm 0.6[-0.1 ; 0.4]$ & $0.1 \pm 0.4[-0.1 ; 0.3]$ & $5.2 \pm 20.0[-4.2 ; 14.6]$ & $2.7 \pm 9.6[-1.8 ; 7.2]$ & $P$ vs L: $P=0.789$ \\
\hline $\mathrm{HT}_{5} \mathrm{~mm}$ & $0.2 \pm 0.6[-0.1 ; 0.5]$ & $0.4 \pm 0.6[0.1 ; 0.7]$ & $8.4 \pm 20.8[-1.3 ; 18.2]$ & $12.0 \pm 15.3[4.8 ; 19.1]$ & $P$ vs $L: P=0.100$ \\
\hline \multicolumn{6}{|c|}{$\begin{array}{l}\text { HTxmm, horizontal thickness of the augmented region measured } \times \mathrm{mm} \text { apical to the implant shoulder; SD, standard deviation; } 95 \% \text { Cl, } 95 \% \text { confidence } \\
\text { interval. } \\
\text { "P" = Particulate bone substitute alone (control); "L" = L-shaped soft-block bone substitute (test). } \\
\text { * Results of repeated-measures ANOVA with Greenhouse-Geisser correction. } \\
\text { †Statistically significant. }\end{array}$} \\
\hline
\end{tabular}

Table 3 


\begin{tabular}{|c|c|c|c|c|c|c|}
\hline \multirow[b]{2}{*}{ Treatment modality } & \multirow[b]{2}{*}{ Parameter } & \multirow{2}{*}{$\frac{\text { Before suturing }(\mathrm{mm})}{\text { Mean } \pm \text { SD }[95 \% \mathrm{Cl}]}$} & \multirow[t]{2}{*}{ After suturing $(\mathrm{mm})$} & \multirow[t]{2}{*}{ Change $(\mathrm{mm})$} & \multirow[t]{2}{*}{ Change $(\%)$} & \multirow[b]{2}{*}{$P$-value } \\
\hline & & & & & & \\
\hline \multicolumn{7}{|l|}{ Test (L-Shaped) } \\
\hline Highest Point & & $3.6 \pm 0.6[3.3 ; 3.9]$ & $2.6 \pm 0.6[2.3 ; 2.9]$ & $-1.0 \pm 0.5[-1.2 ;-0.8]$ & $-28.0 \pm 11.9[-33.6 ;-22.5]$ & $<0.001+(*)$ \\
\hline $45^{\circ}$ thickness & & $4.2 \pm 0.6[3.9 ; 4.4]$ & $3.1 \pm 0.6[2.9 ; 3.4]$ & $-1.0 \pm 0.5[-1.2 ;-0.8]$ & $-24.8 \pm 10.2[-29.6 ;-20.0]$ & $<0.001+(\$)$ \\
\hline \multicolumn{7}{|c|}{$\begin{array}{l}\text { n, number; HTxmm, horizontal thickness of the augmented region measured } \times \mathrm{mm} \text { apical to the implant shoulder; CM, Collagen membrane; SD, standarc } \\
\text { deviation; } 95 \% \mathrm{Cl}, 95 \% \text { confidence interval. } \\
\text { * Results of repeated-measures ANOVA with Greenhouse-Geisser correction. } \\
\text { \&Results of non-parametric Wilcoxon test with Bonferroni correction } \\
\dagger \text { Statistically significant }\end{array}$} \\
\hline
\end{tabular}

\section{Table 4}

\begin{tabular}{|c|c|c|c|c|}
\hline Factor(s) & Mauchly's sphericity & $\mathrm{F}$ & df & $P$-value* \\
\hline (1) Treatment modality§ & 1.000 & 0.006 & 1 & 0.942 \\
\hline (2) Apico-coronal level $\ddagger$ & 0.001 & 43.415 & 1.762 & $<0.001 \dagger$ \\
\hline (3) Suturing & 1.000 & 3.241 & 1 & 0.088 \\
\hline$(1) \times(2)$ & $<0.001$ & 0.855 & 1.271 & 0.390 \\
\hline$(1) \times(3)$ & 1.000 & 0.099 & 1 & 0.757 \\
\hline$(2) \times(3)$ & 0.008 & 26.336 & 1.805 & $<0.001 \uparrow$ \\
\hline (1) $\times(2) \times(3)$ & 0.006 & 0.941 & 2.034 & 0.400 \\
\hline \multicolumn{5}{|c|}{$\begin{array}{l}\text { (1), Treatment modality; }(2) \text {, Apico-coronal level; }(3) \times \text {, interaction between } \\
\text { degrees of freedom. } \\
\text { *Results of repeated-measures ANOVA with Greenhouse-Geisser correction. } \\
\text { † Statistically significant. } \\
\ddagger 0-5 \mathrm{~mm} \text { apical to the implant shoulder. } \\
\S \text { GBR procedures. }\end{array}$} \\
\hline
\end{tabular}

\section{Table 5}




\begin{tabular}{|c|c|c|c|c|c|}
\hline & \multicolumn{2}{|l|}{ Change $(\mathrm{mm})$} & \multicolumn{2}{|l|}{ Change (\%) } & \multirow[b]{3}{*}{ Statistical analysis* } \\
\hline & 1st study & 2nd study & 1st study & 2nd study & \\
\hline & \multicolumn{4}{|l|}{ Mean \pm SD $[95 \% \mathrm{Cl}]$} & \\
\hline $\mathrm{HT}_{0} \mathrm{~mm}$ & $-0.5 \pm 0.5[-0.7 ;-0.3]$ & $-0.6 \pm 0.5[-0.8 ;-0.3]$ & $-22.9 \pm 21.2[-32.8 ;-13.0]$ & $-20.5 \pm 23.2[-31.4 ;-9.7]$ & 1 vs $2: P=0.702$ \\
\hline $\mathrm{HT}_{1 \mathrm{~mm}}$ & $-0.2 \pm 0.4[-0.4 ;-0.1]$ & $-0.3 \pm 0.5[-0.5 ;-0.0]$ & $-6.9 \pm 12.5[-12.8 ;-1.0]$ & $-7.4 \pm 17.1[-15.4 ; 0.6]$ & 1 vs $2: P=0.767$ \\
\hline $\mathrm{HT}_{2} \mathrm{~mm}$ & $-0.1 \pm 0.3[-0.2 ; 0.1]$ & $-0.0 \pm 0.5[-0.1 ; 0.3]$ & $-0.9 \pm 10.5[-5.8 ; 4.0]$ & $1.0 \pm 16.8[-6.8 ; 8.9]$ & 1 vs $2: P=0.861$ \\
\hline $\mathrm{HT}_{3} \mathrm{~mm}$ & $0.1 \pm 0.3[-0.1 ; 0.2]$ & $0.1 \pm 0.5[-0.1 ; 0.3]$ & $3.3 \pm 11.0[-1.8 ; 8.5]$ & $5.3 \pm 16.3[-2.4 ; 12.9]$ & 1 vs $2: P=0.830$ \\
\hline $\mathrm{HT}_{4} \mathrm{~mm}$ & $0.0 \pm 0.4[-0.1 ; 0.2]$ & $0.1 \pm 0.6[-0.1 ; 0.4]$ & $2.2 \pm 12.0[-3.5 ; 7.8]$ & $5.2 \pm 20.0[-4.2 ; 14.6]$ & 1 vs $2: P=0.573$ \\
\hline $\mathrm{HT}_{5} \mathrm{~mm}$ & $0.0 \pm 0.3[-0.1 ; 0.2]$ & $0.2 \pm 0.6[-0.1 ; 0.5]$ & $1.6 \pm 12.1[-4.1 ; 7.3]$ & $8.4 \pm 20.8[-1.3 ; 18.2]$ & 1 vs $2: P=0.236$ \\
\hline \multicolumn{6}{|c|}{$\begin{array}{l}\mathrm{HT} \text { xmm, horizontal thickness of the augmented region measured x mm apical to the implant shoulder; SD, standard deviation; } 95 \% \text { CI, } 95 \% \text { confidence inter- } \\
\text { val; "1"=1st study; "2" }=2 \text { nd study. } \\
\text { *Results of repeated-measures ANOVA with Greenhouse-Geisser correction. } \\
\dagger \text { Statistically significant. }\end{array}$} \\
\hline
\end{tabular}

Table 6 